\title{
LA EXPERIENCIA (Y CONTEMPLACIÓN) DE LO SAGRADO EN LA OBRA POÉTICA DE ANDRÉS SÁNCHEZ ROBAYNA
}

\author{
Juan José RASTROLLO TORRES \\ IES Vila de Gràcia de Barcelona \\ jjrastrol@gmail.com
}

Lo inexpresable, ciertamente, existe. Se muestra, es lo místico.

L. Wittgenstein

\begin{abstract}
Mientras tenemos el sentimiento del misterio, conservamos implícitamente una dimensión religiosa. Pues ser religioso es sentir el misterio, incluso fuera de toda forma de fe.
\end{abstract}

E. Cioran

$\Gamma$ Tras la pérdida de los dioses, lo sagrado se ha ido vinculando en nuestro tiempo al misterio, a la creencia, la metafísica de lo visible y, en definitiva, al pálpito de lo invisible. Palabras como estas de Wallace Stevens lo refrendan: «Es la creencia, y no el dios, lo que cuenta» (2006: 245). En el caso de Andrés Sánchez Robayna, gran parte de las flechas de sentido que recorren su obra convergen en torno a lo sacro entendido como indagación misteriosa y punto de encuentro del mundo exterior con el interior: «Desde algún tiempo atrás, no concibo o no podría concebir ninguna escritura ajena a la idea y al espacio de la sacralidad» (1996: 200). De este modo, en su poética precisa entenderse la idea de lo sacro (y de la misma experiencia mística) de manera aconfesional, desligado de una religión concreta y en la línea definida por Marcel Viller: «l'expérience du tout autre» (1990: 38). Y, sobre todo, como la conciencia y la forma de expresión de «la sobreiluminación»o «lo espiritual poético» ${ }^{1}$. En esta aproximación a la idea y permanencia de la sacralidad en su obra, son significativas, en mi opinión, estas palabras del autor reflexionando sobre si la presencia de Dios y de su espacio ha sido sustituida hoy por el lenguaje:

El núcleo de ese problema, sin embargo, no es, como pudiera pensarse, la sustitución en sí, sino el hecho de que lo sagrado, a pesar de todo permanece. Esta es para mí la cuestión clave. Que hayamos puesto el lenguaje en lugar de Dios, que el lenguaje haya ocupado su espacio, es una traslación que preserva, en efecto, la presencia de lo sagrado. [...] Es el sentimiento de lo sagrado el que nos acompaña (¿aún?), y el

\footnotetext{
${ }^{1}$ En el artículo, «San Juan de la Cruz: destrucción y destino», Sánchez Robayna aporta una valiosa información sobre su interpretación de lo místico, definiendo así lo que él llama «espiritual poético»: «¿Es el sentido místico un no-sentido? Parece obligado, en nuestra perspectiva de hoy, hablar no ya de sentido místico, sino de lo espiritual poético como el centro o el objeto de esta experiencia-límite.» (1992: 8). Es decir, en Sánchez Robayna (como en Valente), el esquema del poema místico es consustancial al propio esquema de la poesía, y no pueden diferenciarse; pero, mientras el místico pretende llenar el vacío de Dios, el poeta que sólo horada lo sagrado busca llenar ese mismo vacío de una realidad otra.
} 
que debe acompañarnos si es en esa redención de la vida en la que ciframos nuestra preocupación y el sentido de la alegría y el dolor humanos. Es en ese sentido, me parece, en el que, recientemente un pintor como Tàpies, tan cercano a la experiencia de lo sagrado, ha podido decir que «aunque se habló mucho durante un tiempo de que hay que desacralizarlo todo, en mi opinión es al revés». (Santa Ana, 2002: 42)

\section{Junto a Ramon Xirau, Juan Antonio Masoliver y Claire Laguian, Claude Le Bigot ha sido uno} de los estudiosos que mejor ha definido el sentido fenomenológico de lo sagrado en la poesía del poeta:

Pour le poète canarien, l'expérience du sacré est le résultat de son immersion dans le monde, et de la perception du caractère immanent du sensible. Autrement dit, son expérience du sacré présente un caractère phénoménologique [...] Robayna n'invite pas ses lecteurs au rêve indéfini de l'excarnation, mais au contraire il les invite à se pencher sur les objets les plus simples et les plus familiers de son environnement, qui sont susceptibles de lui procurer une émotion vive et puissante. Il ne serait pas déplacé de dire que son sens du sacré se manifeste à travers une forme de panthéisme consubstantielle aux liens que le sacré entretient avec la matière, pourvu que l'on prête attention à la proximité du poète avec les éléments naturels. (Le Bigot, 2015: 65)

Pero, en esta reflexión inicial, cabe preguntarse cuáles son las modulaciones de lo sagrado en la obra poética de Sánchez Robayna y qué sentidos convergentes se trenzan entre sus versos. Hago mención de las siguientes: el quietismo, el trascendentalismo, el helenismo, el estado de hiperconciencia zen, el Zohar, el sentimiento oceánico ${ }^{2}$, el concepto de «religación» zubiriana, el misticismo ${ }^{3}$ cristiano y, sobre todo, la metafísica del silencio como posibilidad del comunicar, y espacio que incita a la gestación de toda nombradía poética.

Para entender en qué sentido opera la sacralización del mundo en Sánchez Robayna, hay que partir de una definición de los sustratos de sacralidad de su poesía: los axis mundi o centros de latencia que -en palabras de Bonnefoy- «hablan de una boda entre el cielo y la tierra» (2014: 118). Es decir, se trata de localizar aquellos ámbitos donde el poeta experimenta -en la realidad física- lo que Eliade llamaba «hierofanía», o espacio de reflexión y de encuentro entre la realidad visible y el espíritu. Esto conlleva una forma diferente de estar en el mundo, una atenta espera de la llamada de lo sagrado, la contemplación (cum+templum) de un hallazgo y, finalmente, la visión y formulación de su forma expresiva: «la palabra que sea alumbramiento» (Sánchez Robayna, 2004: 12). Además, esta cuestión de la imagen de la palabra, ya planteada por Kandinsky, es axial en su poética, ya que

\footnotetext{
2 Término acuñado por Koestler (aunque heredado de Romain Rolland, en su carta de 1927 a Freud) que transcribe la celebración epifánica de un saber oculto, en el sentido de la experiencia en nuestro mundo del Absoluto, de la sensación de eternidad y de lo sagrado en la línea de la lezamiana «teleología de lo insular».

${ }^{3}$ Aunque, en el caso particular de nuestro poeta, no podamos hablar de experiencias extáticas en sentido estricto, con el término «mística» (del griego mystikós, cerrar la boca y los ojos; y de mistérion, secreto y ocultación) nos referiremos más bien a una mística natural y profana, es decir a un redescubrimiento de «lo religioso» al margen de toda doctrina. $\mathrm{O}$, diciéndolo con Marcel Viller: «certaines réalités, mots, choses, temps, espaces peuvent acquérir la valeur du sacré lorsque se manifeste en elles ce qui peut être assimilable à l'efficacité de la puissance divine et entraîner un surcroît d'être» (1990: 38). O finalmente, de lo que Kandinsky definía como la naturaleza mística de la obra de arte y la necesidad de mirar (y oír) la vida interior de lo exterior: «La verdadera obra de arte nace misteriosamente del artista por vía mística.» (1982: 113). La obra de Andrés Sánchez Robayna, más que una poesía mística que exprese la abolición de la dualidad cuerpo-espíritu, se podría considerar poesía ascética ya que, al margen del sentimiento de desprendimiento de lo humano y de purificación respecto a lo prosaico de este mundo, representa el escribir desde la calma y la complacencia de un mirar lento a ese mismo mundo. A esto se añade, además, una presencia absoluta del silencio o de estados de ánimo silentes.
} 


\section{Tropelías. Revista de Teoría de la Literatura y Literatura Comparada, 29 (2018) 61 La experiencia (y contemplación) de lo sagrado en la obra poética de Andrés Sánchez Robayna}

da respuesta a la interpretación de muchos de los versos del poeta: «Así como la palabra pronunciada (árbol, cielo, hombre) provoca una vibración interior, todo objeto representado en imagen provoca una vibración interior» (Kandinsky, 1982: 69).

En Día de aire (1970), poema en nueve fragmentos, ya se aprecia este proceso de resacralización del mundo. El niño-poeta, imantado por la latencia de lo sagrado, deambula con mirada asombrada por un paisaje insular desde el amanecer hasta la oscuridad: «La mañana / sobre los médanos te llama / a la busca del aire, al dominio del sol» (2004: 11). En el poema «Escena» de su segundo libro, Clima (1972-76), sitúa en el centro del mar («divino centro que engendra infinitos círculos concéntricos») el espacio de encuentro con lo eterno y con la palabra revelada: «En el centro del flujo / del mar, miro el incendio» (2004: 20). En «Para el viento nocturno» describe una experiencia de vuelo arrebatado en la arcana noche: «Establecimientos de la noche, / los signos de la noche antigua. / Yo entro en esa posesión como por un espacio ennegrecido / de cielos rápidos. / Se dispersa el espacio.» (2004: 34). Por último, en «Lectura insular» experimenta algo parecido al sentimiento oceánico: «El poema / fue el vislumbrar cegado / la escena del sol» (Sánchez Robayna, 2004: 41).

En el poema «Unidad», de su libro Tinta (1978-79), cristaliza otra de las variaciones de la expresión de lo sagrado según la cual la senda de la ignorancia y del «inconocimiento» se imbrican al hecho poético:

Agua nocturna abajo -la noche: un pasadizo hasta el vértice oscuro de las transfiguraciones-, se abre, en el pasaje más negro de tu cuerpo, agua nocturna abajo, una noche más negra, pendiente de la nuca en la que me sumerjo, ladera fija del desconocimiento, noche en el seno de la noche» (2004: 99).

Se me figura que, en estos versos, el poeta hace presente la influencia de Plotino en el sentido de que el conocimiento no procede de lo inmediato, sino de una comprensión posterior a la experiencia de lo sagrado. Se trata, en definitiva, de un conocer desde la senda de la ignorancia. En «El vaso de agua», como si de una teología de la mirada se tratase, el poeta penetra en la dimensión metafísica de la calma, la transparencia y el silencio. En esta composición, la experiencia de lo sagrado prorrumpe en la vida cotidiana a partir de un objeto-enigma ${ }^{4}$ («Un solo vaso de agua alumbra el mundo», Jean Cocteau), que es la manifestación misteriosa y simbólica de la quietud, y lo eternamente bello:

El vaso de agua es un ensayo de quietud. [...] El sol bebe con un sorbo invisible. El sol sin uñas, quieto y rasgado. El vaso está en reposo bajo el sol. Y bajo la mirada, erguido y soleado. El vaso es la mirada. El vaso quieto bajo el sol rasgado. Todo sucede en su ausencia. (2004: 100).

Como acontece con Wallace Stevens y su obra homónima, la escritura del poeta canario se torna más espiritual (¿religiosa?) -en el sentido de una búsqueda del Absoluto en este mundo- a partir de su libro La roca (1980-83); pero, insisto, se trata de una espiritualidad ecuménica y no

\footnotetext{
${ }^{4}$ Este es el sentido (el de objeto que desvela lo sagrado en lo real) en el que también lo entienden Mircea Eliade o Giordano Bruno, es decir como un objeto de magia: «Un objeto será sagrado siempre y cuando incorpore (es decir, revele) algo distinto a lo que es» (Eliade, 1998: 15).
} 
confesional, al margen de la tradición judeo-cristiana. En «Para tres voces», suenan coros de música sacra en un día de enero mientras las sombras y luces del exterior van avanzando, ocupando el espacio de la luz del cuarto (analogía del mundo) del poeta: «los coros se detienen la luz llega hasta el cuarto la luz del sol final» (2004: 132). «A una roca» ilustra la definición que Eliade hizo de la «hierofanía» de la roca como símbolo metafísico de la eternidad, la unidad sagrada, la comprensión cíclica, la quietud, el silencio y, en definitiva, el Todo: «negro tranquilo de la forma: / las lisas aristas fluyeron / calma fluida lisa negra / soledad entera de la forma» (2004: 145). En «La ventana. Estrellas», la noche estrellada es el escenario de la inminencia de la revelación de un mundo que nos habla, y de la presencia de la palabra como iluminación oscura de tinta, como luz negra escrita en el cielo estrellado en forma de silabario: «luz de / estrellas: / el / brillo de / gotas / alcánzame / alcánzame / luz / negra» (2004: 136). También en «Cita» asistimos a la contemplación arcana de lo oculto «allá arriba», tras la oscuridad nocturna: «sopla la luna el mar plisado: / antigua noche me da cita / sobre las aguas mira un niño / la noche antigua de allá arriba» (2004: 141). El muro (simbolizando la experiencia de lo ilimitado y la eternidad) es otro de los centros de latencia de lo sacro. En el poema «Muro», de Tríptico (1985), la contemplación de un viejo grafito sobre la pared desconchada de un atrio le hace meditar sobre la naturaleza del tiempo: «paseas por el centro / del tiempo el sol / tú pronuncias el tiempo / sobre los muros desconchados [...] paseas por los siglos / en tu grafito / el tiempo te pronuncia» (2004: 187). Como en Edmond Jabès, el muro se erige como imagen de la ocultación y custodio de lo arcano, adquiriendo así cierta transcendencia como memoria del ser antes de la existencia: «Muros de la ciudad que la luz agujerea, a esta hora, desde el interior. El misterio los habita» (Jabès, 2002: 46).

Palmas sobre la losa fría (1986-88) será el libro donde con mayor claridad cristalice una poesía metafísica de tono mítico (y místico). El mismo epígrafe de San Juan que abre el poemario lo anuncia: «Su claridad nunca es escurecida, / y sé que toda luz de ella es venida». Aquí el ámbito sagrado donde el poeta se sumerge para desencriptar el primigenio sentido de las palabras es el del no-tiempo y el no-lugar, un espacio donde sólo hay presencia de silencio y quietud. En cierto sentido, esta idea de tiempo sagrado se corresponde con el espacio silente «fuera del acontecer» que Edmond Jabès declaraba a Marcel Cohen en una entrevista:

Nosotros no podemos imaginarnos fuera del tiempo o del acontecer. Toda nuestra cultura nos emplaza en el tiempo. Ved los anacoretas, por ejemplo: están más muertos que vivos, literalmente quemados por el silencio. Sólo los nómadas, una vez más, saben transformar ese silencio aplastante en fuerza de vida. (Jabès, 2002: 9)

En el poema «La espera, al sol», resuenan también ecos de Jabès, en esa espera de la revelación (y escucha) de la sobreiluminación de la naturaleza a través de «la luz irisada de la Nada»: «¿Quién gritaba en los surcos, quien veía, / bajo la soledad del sol sin la presencia, / cegado y solo un mundo sin respuesta, sin voz?» (2004: 213). Como en el caso del desierto jabesiano, el espacio poético insular de Sánchez Robayna se halla intersticialmente entre el mundo sagrado y el profano; o, diciéndolo con Bonnefoy, en un arrière-pays (simulacro de mundo ultraceleste de las ideas) 
luminoso y silencioso, que -gracias al acto de fe y la creencia en un sueño- hace posible aquí la huida de este mundo. Así se aprecia también en «Luz de Fuerteventura», donde el poeta relata un paseo a través de la irisada luz insular y de la eternidad de los páramos majoreros. En el poema subyace además el pensamiento gnóstico de Plotino, sobre todo en la identificación espíritu-luz y en la referencia a la suspensión del espíritu -a través de un vuelo en círculos concéntricos de luz- hacia una naturaleza inteligible:

\author{
[...] Caminamos. \\ Entramos a otra luz, a otro silencio. \\ El cielo es negro. El viento \\ sopla los arenales, mano \\ de salitre en el rostro. Casi ciegos \\ avanzamos por lindes destruidas, \\ el malpaís de piedra roja, zarzas \\ quemadas, tierra ardida. Vimos \\ el sol fundirse al pedregal oscuro.
}

¿Fue el sueño de una tierra herida, luz

disipada de pronto para ver

tras la luz el sentido de la luz?

Otra tierra, y la misma [...] (2004: 202)

En «La roca» («Casa del dios oculto, negra / morada pétrea porque vea / el hombre allí su fortaleza. / Naciente o dios oscuro, fijo, / porque allí vea su sentido, / la luz en paz y su destino» (2004: 212)); o, de otra manera, en «A una roca» («Dinos tu calma y tu silencio, / oh inmóvil oh vertiginosa. / Bebemos luz. El dios dormita. / Bebemos, dios de claridad.» (2004: 253)), la oquedad del elemento mineral se vierte como espacio de meditación y centro de gravedad divino desde donde descender al fondo del yo para -en esa catábasis atenta de abandono de la razón- aniquilarse y suspenderse en lo Uno. Se trata de un proceso que la estudiosa Claire Laguian identifica con un «inscrire l'univers dans la permanence du mineral» (2015: 290). El poema de la segunda serie, «La barca» (naos, también 'templo' en griego), condensa todo el imaginario de la tradición mística, en el sentido de viaje hacia lo sagrado bajo la inmersión en el no-tiempo del umbral del suceder. Con este símbolo, se plantea en cierto sentido la idea mística del nacer a la muerte: «Iba sobre las aguas aquietadas / del sueño nuestra barca, era una sombra / suspendida. Latían, en el sueño, / la barca, la quietud, la luz, las aguas» (2004: 221).

En la cuarta serie del poemario, en «En este cuarto», la presencia de lo sagrado se aprecia como en la parábola de San Buenaventura sobre la circularidad temporal- en el lienzo de la visión poética de la lluvia ${ }^{5}$ sobre el mar, lo cual nos conduce a una reflexión sobre el eterno recomienzo del tiempo: «Ves esa lluvia? ¿Ves su leve abrazo, / cómo abriga los mundos, las cortezas, / las hojas poseídas, y las casas, y el cielo / dador, tan cerca ahora, y la tierra en su enigma?» (2004: 235). La nube y el pájaro se erigen también como baluartes de la sacralidad en «Al cúmulo de octubre», uno de los poemas donde mejor se describe el vuelo místico del espíritu hacia la luz: «Al cúmulo en el

\footnotetext{
${ }^{5}$ Esta imagen será retomada en el inicio de El libro, tras la duna.
} 
cielo, hasta la sola / nube de octubre, sube, / sube los ojos, sube / igual que un ave sosegada sube.» (2004: 242). O en «De una hoguera», celebración del alumbramiento y el abrazo extático bajo la «ignición del mundo», encarnación de la comunicación con lo divino y centro invisible y origen primero del Todo: «Vuelve a arder el verano en esas brasas, / en la rueda de fuego. Arde la estrella, / crepita la morera, el mar rojizo, / la sed del fuego en la unidad del fuego.» (2004: 246). No debemos obviar que la experimentación de lo sagrado en la poesía de Sánchez Robayna se ve imbuida además por la acepción zubiriana de re-ligación, en el sentido de ligadura del ser del hombre con el ser de las cosas (y con el cosmos); pero también por la alianza y la reconciliación de la palabra con la Nada que es origen del Todo. En el poema «La llamada», de Inscripciones, la inminencia de la palabra sagrada y su revelación ex nihilo tienen como leitmotiv la lámpara de fuego, símbolo de comunicación con lo divino: «Enciendes una lámpara / en la ventana. Yace / la noche alrededor. / Llueve en silencio. / ¿Para quién esa luz? / ¿Para la noche? / Una lámpara llama / en la calma nocturna.» (2004: 342). Así se muestra también en «Para la llama de una vela», donde la luz tenue de una vela («la llama oscura» del desconocimiento), sobre una mesa de trabajo de un «cuarto a oscuras», convoca la «llama visible» de un relámpago nocturno en agosto. La voz poética de san Juan de la Cruz y todo su ideario de despojamiento místico ( «Se extingue aquí una vela / encendida en su nada, en la pobreza, / en el origen, llama llamadora» (2004: 239)) parecen concentrarse en estos versos:

Y el relámpago
cruzó a lo lejos, signo breve, llama
abrazada a esta otra: de una vela
brota en silencio el resplandor
que apenas ilumina y que parece
volver la oscuridad aún más oscura.
Sola llama visible que convoca
a lo invisible, lengua de silencio
pobre, vencido, solitario; luz
de oscuridad, de desconocimiento. (2004: 238)

La imagen del rayo metafórico y su cegadora explosión de luz, como manifestaciones de lo sagrado en la Naturaleza, y de la celebración de la comunión con lo divino en este mundo a través de él, proceden de la mitología griega y de Heráclito, que consideraba al rayo y al trueno como un canto celeste de la tormenta divina (las «tormentas del dios» (2002: 191) precipitadas desde las alturas, del himno «Como cuando un día de fiesta» de Hölderlin). Este motivo recurrente reaparecerá posteriormente en el poema «El rayo verde», en La sombra y la apariencia, donde -como en Le rayon vert de Éric Rohmer o en la novela de Jules Verne- el paseante aguarda el pálpito de su destello como quien espera una revelación de lo oculto y un llamamiento hacia otras realidades invisibles: «El rayo va a formarse / bajo el cielo silente. / Late el ojo del sol. / El aire se estremece. / [...] En el borde del astro, / bajo la luz que hierve, / el horizonte espera / el rayo de oro verde.» (2004: 209). Es inevitable además percibir - en esa presencia de la metáfora del rayo «que lo 


\section{Tropelías. Revista de Teoría de la Literatura y Literatura Comparada, 29 (2018)}

La experiencia (y contemplación) de lo sagrado en la obra poética de Andrés Sánchez Robayna

gobierna todo»- ecos de «Oración» ${ }^{6}$ de George Herbert, cuando se refiere al «trueno invertido» que vuelve al cielo como imagen de la vuelta al origen: «Volverá ese relámpago al origen, / o a su nada, a su nube de latidos, / y la materia a su materia madre.» (Sánchez Robayna, 2004: 238). O bien, resonancias del «rayo de tiniebla de infinita escucha» de Valente, centro que es el Todo y el rostro de dios: «El rayo de tiniebla. / [...] Bajé desde mí mismo / hasta tu centro, dios, hasta tu rostro / que nadie puede ver y sólo / en esta cegadora, en esta oscura / explosión de la luz se manifiesta.» (2000b: $60)$.

El siguiente título del autor, Fuego blanco (1989-91), alude al alumbramiento y la nombradía casi por milagro- de la palabra, ya liberada de toda referencialidad. Así se aprecia en el poema «La casa» («Salir hasta la casa, entrar / hacia fuera, a la luz, hasta las aguas / en la espesura adentro en las arenas / de adentro de esta casa en que morir.» (2004: 298)), donde la morada se erige como imago mundi; o en «Signo, vacío», donde el «fuego blanco» es la misma luz blanca y sagrada de El Zohar, aquella que se extingue y (desde su muerte) se transforma en otra luz: «En la llama morir, y renacer / en otra convocada llama viva, / cuerpo, sobre los senos que salpica / el deseo, la luz, los oleajes.» (2004: 263). En el poema homónimo, el fulgor metafísico de la escritura es «luz para ver la luz» (de leukós, blanco y transparente) que anuncia un nuevo entrever:

Ardió durante todo el día, y aún pude ver las brasas sobre los círculos nocturnos. Las piedras hirvieron. Humearon los árboles resecos, los animales se retiraron hasta sus bordes de sigilo. Enrojeció la breve nube única como mancha celeste. Jadearon los muros de desprendida cal. Aún pude ver la luz abrevar en lo oscuro, por los invernaderos destrozados. (2004: 238)

Otras variaciones de la presencia del ámbito de lo sagrado con especial calado en este libro son el silencio y el vacío convocándonos a una nueva dimensión de la $\mathrm{Nada}^{7}$. La crítica ha prestado oídos a esta cuestión fundamental para la exégesis de la poesía robayniana. Así lo entiende también Jenaro Talens:

En la mejor tradición de Juan de Yepes, sor Juana (a la que ha dedicado un novedoso estudio) y José Ángel Valente, sus versos intentan decir el silencio del que surgen y al que irremisiblemente conducen. Pero es un silencio que, como afirmaba Jacques Ancet a propósito de Cántico espiritual, no es el de «la suspensión de las palabras, sino el del silencio del sentido». (2000: 313)

De ese modo se muestra también en el largo poema «Una hoguera, y el centro de la muerte»: «¿Incomprensible? Nada, / entre lo audible y lo inaudible / entre lo oído y el oído / entre el silencio y lo que oímos / un canto oscuro, nada más / escuché por la hierba, un canto oscuro» (2004: 274). O en

\footnotetext{
${ }^{6}$ «Cerco contra el Altísimo, torre de pecadores, / trueno invertido, lanza que a Cristo en el costado hiere, / los seis días del mundo que en una hora muda, / canto que toda cosa escucha y teme; [...] Campanas más allá de las estrellas, sangre del alma, / país de las especias; algo entendido.» (Herbert, 2014: 29).

${ }^{7}$ Sobre el origen y la trayectoria descendente y abisal de la palabra poética hacia el origen, me parecen iluminadoras estas palabras de Nilo Palenzuela: «La "nada moderna" (Mallarmé) en la que refulgen el absoluto y la utopía toca con la mano la fugacidad misma del hombre y sus expectativas. La poesía surge entonces como sobreiluminación, fuego, llama, conocimiento, mismidad lumínica, que traspasan esta poesía en una suerte de espiral descendente, hacia su centro, hacia su matriz imaginaria y poética.» (1993: 27).
} 
«La hoguera», donde el silencio ${ }^{8}$ (como en el pensamiento místico) es constitutivo consustancial a la palabra poética, y espacio abisal de creación desde el que partimos y hacia el que nos dirigimos tras el poema:

\author{
Un silencio \\ se apoderó, fulmíneo, de la casa, \\ penetró los ramajes estuosos, \\ un preludio, un vacío, ante la llama. \\ [...] La luz quemada como brasa oscura, \\ sobre los arenales, sobre el mar, \\ como un fuego en el cielo, y el temblor \\ de la luz en la tela, la nada que vendrá. (2004: 262).
}

Según se avanza en la trayectoria del poeta, surgen nuevos escenarios de la sacralidad. Del mismo modo que lo fue el muro, en «El resplandor», una pirámide («la piedra henchida») es ahora el espacio sagrado que «malogradamente» imbrica el mundo real con el misterio, manifestando de este modo el poder de la infinitud: «Bajábamos. Sólo entonces supimos que aquella construcción se alzaba entre la tierra y el cielo como imposible lugar de mediación entre la humana lengua y la lengua de dios» (2004: 283). Diciéndolo con Fernández Casanova:

En «El resplandor» nuestro autor aboga por una sacralidad ajena a cultos y dogmas. La pirámide del poema, visitada por el yo, es el contrato establecido entre el dios y los antiguos habitantes del lugar, la ofrenda de estos a cambio de la protección, el agua y la palabra del dios. En el descenso de la misma, el protagonista observa un tímido resplandor, inmediatamente ahogado, «en busca de la humana mirada». Es cuando se da cuenta de la insuficiencia de la pirámide como «lugar de mediación entre la humana lengua y la lengua del dios». (2005: 156)

En el epígrafe final de Fuego blanco, unos versos de Juan Ramón («un dios en ascua blanca [...] / en la mañana oscura») anuncian el sístole y diástole de los poemas de su libro posterior, Sobre una piedra extrema (1992-95). En el texto que da título al libro, el poeta retoma el sentido arcano de la piedra como totalidad («Al pie de la ladera, los mundos reunidos, / como los une un libro» (2004: 330)) y símbolo de centro gravitacional en torno al principio y a su fin: «¿O es que era, lo que llamo comenzar, / la conciencia primera / del fin, una inscripción contra la muerte / de la luz?» (2004: 330). En este sentido lo entiende también José Ángel Valente: «La piedra y el centro son, en verdad, lo mismo» (2000a: 17). De nuevo, la palabra se presenta al poeta como «signo» o «señal», en el sentido

\footnotetext{
${ }^{8}$ En el artículo «La pregunta por la palabra» (2007), Sánchez Robayna presta relevancia a la cuestión de la materialidad invisible y de la trascendencia del silencio: «Palabra y silencio, en efecto, en diálogo mutuamente fecundante. "El silencio - escribe Paolo Valesio- es la situación ontológica común a toda poesía; es la condición para que surja poesía.” Y añade: "Del mismo modo que el sueño es esencial para el mantenimiento de la vida física, el silencio es crucial para el desarrollo de la vida espiritual”...» (2008: 336). Por otra parte, en la concepción del silencio en nuestro autor, cabe reseñar también la notable influencia de Maurice Blanchot: «Lo Sagrado no puede ser captado directamente, menos aún convertirse en habla, pero, merced al silencio del poeta, se dejaría apaciguar, transformar y finalmente transportar hasta el habla del canto [...] Sucede que el silencio está marcado con la misma contradicción y el mismo desgarramiento que el lenguaje: si es una vía para aproximarse a lo inaproximable, para pertenecer a lo que se dice, sólo es "sagrado" en tanto en cuanto hace posible la comunicación de lo incomunicable y desemboca en el lenguaje: "que lo sagrado sea mi palabra" (Hölderlin); tenemos aquí la llamada del poeta, y las palabras son "santuarios", los templos de lo Sagrado, no el silencio.» (2007: 119).
} 


\title{
Tropelías. Revista de Teoría de la Literatura y Literatura Comparada, 29 (2018)
}

La experiencia (y contemplación) de lo sagrado en la obra poética de Andrés Sánchez Robayna

en que Otto $^{9}$ entiende lo sagrado, es decir como revelación religada a una experiencia externa. En el poema «Más allá de los árboles», vemos cómo la revelación de la palabra va más allá del lenguaje y de su referencialidad:

\author{
Aquella era la lengua de las hojas, la lengua \\ del irrequieto fondo de la luz. \\ ¿Lengua, lenguaje, \\ digo? ¿Una palabra \\ más allá del lenguaje, eso buscaba? \\ Solamente más tarde iba a saberlo, \\ cuando el lenguaje habló, y tan sólo \\ llegó el lenguaje a ser la destrucción \\ de cuanto conocía. Y era, al mismo tiempo, \\ la construcción de todo. Yo volvía \\ otra vez a los árboles, aún \\ no sabía del lenguaje sino sólo su enigma. (2004: 307)
}

También el elemento acústico puede suspender nuestro presente hasta el ámbito de lo sagrado y el centro de «lo perpetuo». Así, en el poema «A Thomas Tallis», se describe una experiencia mística de ascensión a través del embate que alza el castillo transparente de voces de Spem in alium (canto «claro y oscuro a un tiempo»). El movimiento de flujo y reflujo de la ola coral, y su eco tras el silencio, nos devuelven al origen y a la unidad perdida:

un canto alzado hasta la transparencia
de la voz, como si el solo hábito
contuviera el fervor de las criaturas,
como si ya las voces se entregaran
a su solo fluir, y pronunciasen
cielo y tierra, fundidos en la sonoridad.
Sabes, pues, que la música puede
llevarte, como herida irrestañable,
hasta la ola de lo perpetuo, hasta el centro
de ti mismo y del mundo, ya fundidos. (2004: 325$)$

Y a través de la música y su eco también llega la imagen (la luz), porque, diciéndolo con Miguel de Molinos, el oído engendra vista: «Podría extinguirse, acaso, el eco / de estas voces? ¿Podría / extinguirse el origen de toda claridad, / de donde toda la luz procede?» (Sánchez Robayna, 2004: 326). El poema «A una música» describe una experiencia paralela: «Ah, música en el templo de la luz entreabierta, / callada: entro en tu cuerpo. Atravieso los rayos / de tiniebla hasta ti, camino de tu entraña, / ya sin ruido de voces, bajo la oscura luz.» (2004: 335). También en «Una tonada, hace ya muchos años», de Inscripciones (1996-99), la trascendencia religioso-metafísica se alcanza a través del oído: el tañido de una campana (y su salvífica llamada acompasada) guía nuestros ojos hacia el misterio de la urdimbre que hila lo visible y lo invisible, introduciéndonos en el centro

\footnotetext{
${ }^{9}$ En palabras de R. Otto: «Estos testimonios reales, estas maneras de manifestarse y revelarse lo santo, son lo que la religión llama en su lengua signos, señales. Desde los tiempos de la religión más primitiva ha tenido valor de 'signo' todo aquello que fuera capaz de estimular en el hombre el sentimiento de lo santo, de sugerirlo, de promoverlo y hacerlo llegar a expresión.» (2000: 217).
} 
invisible de lo sagrado: «Abiertos / los ojos en lo oscuro, el niño escucha / la campana sonar y hacerse noche. / Y ahora, / sobre el borde del tiempo destruido, / mira, noche, su rostro sumergirse / en lo invisible, el círculo / de cuanto desconoce.» (2004: 349). Uno puede apreciar en estos versos referencias a «La campana hendida» de Baudelaire, donde también el ámbito de lo sagrado se escucha en la ciudad a través de un redoble de campanas que atraviesa el tiempo; o ecos de «Campanas más allá de las estrellas» de Herbert, pues también allí lo acústico (desde el más allá) sobrelleva ese desprendimiento de lo humano que hace que «entendamos algo».

Como sucede en otras composiciones, el encuentro con una obra artística, con unos restos arqueológicos o, en el caso de «La capilla», con un sagrario, aviva -trascendiendo lo meramente cultural- la llamada de lo sagrado desde el origen. En la composición, la epifanía de la visita por la nave de una capilla -habitando un lugar aún por descubrir- hace comulgar al hombre con el espacio de revelación del misterio. En este caso, la misma desnudez, la unidad de la luz y la salvífica trasparencia de la capilla convocan la parusía ${ }^{10}$ de lo sagrado en lo real, y en el tiempo eterno de la historia:

¿Qué te trajo hasta aquí?
No esperabas hallar bajo estos cielos
este otro espacio que te acoge
como seno materno, como casa
en que el ser se refugia ante la tempestad
y es apresado por la luz,
y se convierte en luz
reclinada en los muros, y se junta
a la que se desliza
con suavidad por las vidrieras,
y a través del color es el color
y a través de la luz es transparencia. (2004: 352)

En estas composiciones, vamos asistiendo a un nuevo alumbramiento, consistente en rescatar para este mundo espacios y tiempos sagrados a través de la palabra poética. En este sentido, el poema «En el cuerpo del mundo» («Nos cegaste. Seguimos caminando, / a tientas en lo oscuro, hasta encontrar / para siempre ese cuerpo al que abrazarnos, / la cascada de luz, y ahí está la eternidad» (2004: 358)) ${ }^{11}$ sintetiza (junto al artículo «Deseo, imagen, lugar de la palabra») sus preocupaciones estéticas acerca del llamamiento de lo sagrado:

El poema representa o es una gnosis de o por la palabra; y, al mismo tiempo, una convocación de la presencia. Una convocación que, en rigor, no se aparta en ningún punto del sentimiento y la experiencia de lo sagrado. Puede así la palabra llegar hasta las aguas altas, hasta el cuerpo solar; las aguas -dijo Hölderlin-de sacra sobriedad (Ins heilignüschterne Wasser); allí la mano puede tocar el sol. (2008: 350)

\footnotetext{
${ }^{10}$ En el artículo «Deseo, imagen, lugar de la palabra» (1995), Sánchez Robayna define así el término: «Pues la palabra poética, ¿no nos invita, en verdad, a la parusía, esto es, a la búsqueda de la presencia, al encuentro de lo sagrado en nuestro mundo? ¿No es el logos poético, en su más honda raíz, una metáfora de la encarnación, logos que traduce el mundo y es el mundo?» (2008: 354).

${ }^{11} \mathrm{Al}$ leer estos versos del poeta, resulta difícil no pensar en aquellos otros de «Sobre un rayo de sol invernal», en Tres poemas ocultos de Seferis: «buscas rincones donde la negrura / se ha diluido y ya no aguanta / buscas a tientas la lanza / destinada a traspasarte el corazón / y abrirlo a la luz» (2012: 511).
} 


\section{Tropelías. Revista de Teoría de la Literatura y Literatura Comparada, 29 (2018)}

La experiencia (y contemplación) de lo sagrado en la obra poética de Andrés Sánchez Robayna

También el largo poema autobiográfico El libro, tras la duna (2002) refleja momentos de experiencia y revelación de lo sagrado. En el decurso del status viatoris que trazan sus versos, la estructura interna viene constituida por la mixtura oscilante de instantes de vida capsulados y epifanías que horadan el mysterium y lo habitan poéticamente. En palabras de Gabriele Morelli:

Il libro, oltre la duna è infatti discorsivo e al contempo lirico: è meditazioni che indaga negli elementi puri della natura alla ricerca del luogo epifanico del mistero e del sacro, e soprattutto guarda e interroga la trama segreta delle parole: «Nel fluire mutevole dei giorni / di sillabe segrete un linguaggio / si formava, una trama, rete nera. / Non visibile, un libro andò scrivendosi.» (2009: 62)

Como trasfondo, hay en el poema extenso una presencia absoluta de la vieja metáfora del mundo como libro sagrado: el mundo es un crisol-texto, una escritura cifrada que el hombre lee y descifra según su ocultamiento y mostración. Además de la metáfora del Liber mundi, sobrevuelan los 77 fragmentos que componen esta «autobiografía trascendida» dos leitmotiven supeditados a las ideas de anábasis hacia lo elevado, suspensión de los sentidos y trascendencia: el cielo estrellado y la «nube del no saber». Este último motivo poético reproduce un planteamiento según el cual para acceder a lo que no se conoce hay que partir de la zozobra de la ignorancia o - en palabras de san Juan de la Cruz - de «las profundas cavernas del sentido» (1991: 1005) de Llama de amor viva. En Sánchez Robayna, esta idea del «entender no entendiendo» y la renuncia al conocimiento tienen su raíz en la tradición mística ${ }^{12}$; pero también en la modernidad poética del propio Stevens: «La ignorancia es una de las fuentes de la poesía» (2006: 259):

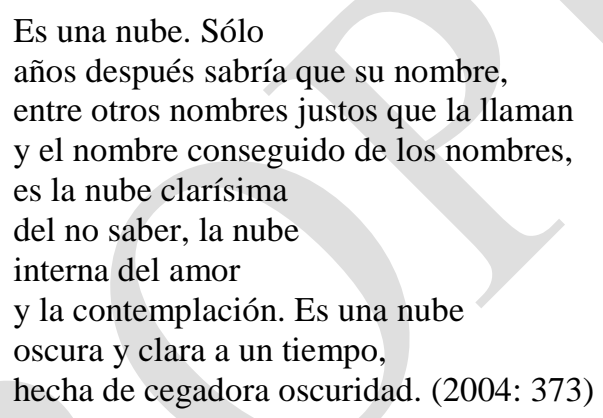

Respecto al mosaico del cielo estrellado representando el tejido misterioso y sagrado del mundo, adquiere presencia en el poema desde aquellos paseos infantiles por La Angostura, en los que el niño-poeta estaba preparando el camino de iniciación a la vida, y el descubrimiento del sentido órfico y numinoso de las palabras:

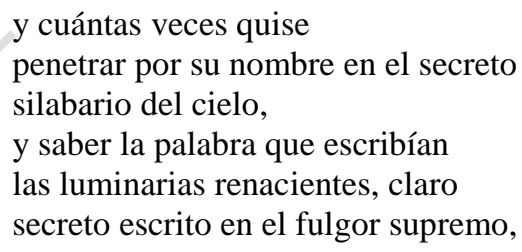

\footnotetext{
${ }^{12}$ El sentido de docta ignorantia aborda toda una tradición que comprende: la Teología mística del Pseudo Dionisio Areopagita; la escuela de místicos especulativos de Ricardo de San Víctor; a místicos alemanes como Nicolás de Cusa (la Docta ignorancia) o el maestro Eckhart («la más alta forma del conocer y del ver es el conocer y el ver, el desconocer y el no ver»); el texto místico inglés del siglo XIV, La nube del no saber; o, por último, san Juan de la Cruz.
} 
En los fragmentos finales del poema se aprecia el planteamiento místico de despojamiento del yo («la desestima del sujeto», de Rudolf Otto) y de vaciado de lo que hemos sido para llegar al «antes del ser», perdiendo así la memoria y volviendo a comenzar de nuevo. Ese aspecto de la despersonalización del propio yo en las experiencias místicas, y ese sentido de aniquilarse en el presente para ir a la nada de antes del yo (donde nada se oye, pero está todo), se muestra especialmente en los fragmentos del LXXIII-LXXVII, donde el yo poético -ya trascendido- es representado por una tercera persona: «el arquero» del opúsculo El zen y el arte del tiro con arco, de Eugen Herrigel. Como en el poema «El blanco» de Valente, el arquero -situado en el no-lugar y la atemporalidad de un «estado de suspensión» ${ }^{13}$ - representa al mismo espíritu puro del poeta (absorto por la tensión estética de la palabra), que acoge - a partir del «vaciado» del yo- un verdadero saber no racionalizado. El fragmento LXXIV sincretiza la mística del wu hsin (no-espíritu) del budismo Zen y la deificatio de otras tradiciones:

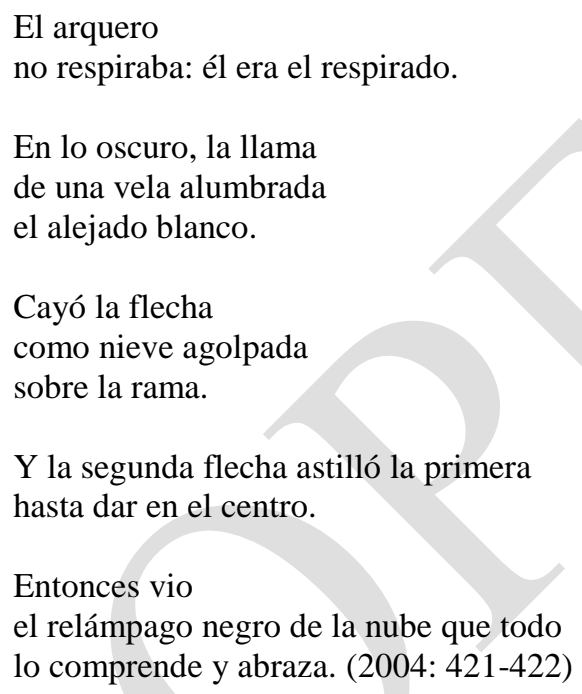

Las siete series poéticas que constituyen La sombra y la apariencia (2002-2010) representan una nueva singladura en el poeta canario, ya que asistimos a la errancia del poeta peregrino a nuevas islas para habitar otros misterios y otras formas de lo sagrado. El título del poemario alude al concepto de «sombra», interpretable desde la contribución exegética de san Juan de la Cruz a Llama de amor viva («Y así estas sombras serán resplandores...» (1991: 821)), según la cual, si la Naturaleza es un reflejo de la Divinidad, las sombras luminosas de lo sagrado también resplandecen en este mundo. Se podría decir que La sombra y la apariencia representa el más claro escoramiento

\footnotetext{
${ }^{13}$ En su «Ensayo sobre Miguel de Molinos», que el poeta canario debió tener muy presente, Valente definía de este modo el fervor de ese estado de gracia: «Estado de suspensión ( $y$ todos mis sentidos suspendía), es decir, de tensión máxima y de máxima quietud, de pasividad y actividad extremas, que podía representar bien el arco armado, en posición de tiro, en el punto de absoluta concentración en que el tirador y el blanco son ya una misma cosa y la flecha es a la vez el movimiento y la inmovilidad. Tal es el estado en que, abolidos la contradicción y lo múltiple, lo que es uno, anterior a toda forma, informe y presente a la vez en todo lo creado, se manifiesta.» (2000a: 93).
} 


\section{Tropelías. Revista de Teoría de la Literatura y Literatura Comparada, 29 (2018) 71 La experiencia (y contemplación) de lo sagrado en la obra poética de Andrés Sánchez Robayna}

de la poesía de Sánchez Robayna hacia las formas de lo místico ${ }^{14}$. En cuanto al término «apariencia ${ }^{15}$, diciéndolo con palabras de Claire Laguian, su sentido se resuelve desde un sistema de armonía de contrarios:

[...] dans le sens de ce qui se cache derrière un aspect trompeur, mais surtout dans l'acception de l'apparaître, du surgissement, comme le suggère la citation de Wallace Stevens qui clôt le recueil robaynien: «Poetry is often a revelation of the elements of appearance.» [...] Ainsi, «la sombra y la apariencia» pourrait ici désigner l'ombre lumineuse nécessaire à l'expérience mystique et sacrée. L'extase intérieure, née de l'opposition structurante du recueil entre ombre et lumière, peut donc être comparée à l'expérience mystique du néant qui «est exaltée jusqu'à ses limites extrêmes, jusqu'à cette «nuit obscure» dont parle St Jean de la Croix, comme moment dernier de l'initiative humaine, qui précède immédiatement l'éventualité de l'extase.» (2015: 284)

En el análisis de Laguian, se localizan ciertos lugares sagrados (iglesias, cementerios, islas...), donde se hace posible - a través de la expiación del ser y la reflexión- la revelación del misterio, situando el punto de encuentro entre el mundo sagrado y el profano. En espacios de revelación tales como una isla (omphalos), un árbol, una playa o una roca, el designio del poeta pasa por el proceso de lo que Laguian llama «une resacralisation nécessaire du Cosmos» (2015: 273).

Por ejemplo, uno de los sentidos en los que opera lo sagrado en La sombra y la apariencia es el de la experiencia y revelación de lo ilimitado, de lo eterno-instantáneo y, en definitiva, del vacío intersticial que hay entre el silencio y la palabra a través de la referencia a un punto (o un instante). Así se aprecia en «A las imágenes de la meditación» ${ }^{16}$, donde se describe la quietud de un momento sagrado de suspensión temporal (centro unificador de los dos mundos) junto a una playa lejana: «Lo visible se cubre de dobles, de espejeos, de ramificaciones. Oh apariencia, tu cuerpo es engañoso» (2010: 21). O, en la misma serie, en el poema «La Alianza», donde medita sobre la presencia de «la masa pura de los intersticios» y la quietud, intuidas aquí a través del reflejo de la luz en un vaso de agua: «[...] en el fulgor de un vaso ves / el reflejo del cielo que arde, el eco de una alianza, / la semejanza que inaugura la forma / en medio de la luz en su expansión» (2010: 32).

La revelación del lenguaje sagrado de la naturaleza tiene especial relevancia en la serie «Sobre una confidencia del mar griego», que transcurre en las Islas Cícladas. En este caso, el «mar respirante» y el enigma de su silencio son quienes comunican el misterio de lo indecible: «Las aguas te decían otra vez / su palabra ignorada» (2010: 93). O ese mismo mar es la lengua mediadora que revela la presencia de los dioses y su mensaje arcano: «Los dioses sonreían en las aguas brillantes. / No mueran esos dioses. Que sonrían, / en lo eterno, y el mar sea su sonrisa» (2010: 79). En estos versos parece que el poeta interpreta lo «numinoso» en el sentido en que lo entiende su admirado Ramon Xirau: «aquello que no podemos definir y que, sin embargo, podemos entrever por medio de

\footnotetext{
${ }^{14}$ En La sombra y la apariencia el misticismo robayniano cristaliza en el sentido en que lo definió Otto: «el misticismo comienza por el sentimiento de una dominación universal invencible, y después se convierte en un deseo de unión con quien así domina» (Otto, 2000: 66).

${ }^{15}$ Avalan también la hipótesis del sentido que atribuimos al término «apariencia» las siguientes palabras de Valente en su artículo «La lengua de los pájaros»: «La palabra poética no es propiamente el lugar de un decir, sino de un aparecer.» (2000a: 240).

${ }^{16}$ Poema incluido en la serie «Inicial, o fracturas de una invitación imperiosa».
} 
una serie de aproximaciones» (2001: 300). Además del mar antiguo, el paisaje insular (y su «círculo eterno») es el espacio fenomenológico más representativo de la revelación de la sacralidad en $L a$ sombra y la apariencia. En el poema que da título a la serie, «En el centro de un círculo de islas», se describe una visita en barco hacia la isla flotante de Delos ${ }^{17}$, isla sagrada de Apolo (la más sagrada del grupo de las Cícladas). Delos emerge como el omphalos («ombligo del mundo») universal ${ }^{18}$, centro-imán y universalis columna que imbrica ambos mundos, reenviándonos al origen. En la composición, el templo de Apolo nos remite a la tradición alegórica de la piedra formulada en términos sagrados, es decir como la eternidad y lo absoluto del ser:

Te hemos visto, tierra, como en un sueño
más vivo aún que el sueño, más real,
entre los bordes de una isla, el fin
de lo que yace en ti, de todo lo que en ti
brota y se extingue,
eres la tierra toda, isla que nos contienes,
isla a la que avanzamos y que vemos venir
a nuestro encuentro
en el centro de un círculo de islas. (2010: 134

El poema «La isla de la noche», en la serie «Urnas y fugas», retoma el concepto de lo «numinoso» ${ }^{19}$ de Otto. Y, especialmente, el «sentimiento oceánico» ${ }^{20}$, al experimentar -tras la revelación de lo sagrado a través de lo invisible- una especie de sensación de dominación universal: «Movimientos. Latidos / sordos de lo viviente. / Cae la noche atlántica. / Salen / de lo invisible suaves animales. / Una danza / anima la madera, la / materia / visible. / Movimientos trenzados / de astros y hojas.» (2010: 211). En el poema «Para llegar a Lipsí», la reflexión del poeta orbita en torno a la misma idea de sentimiento de dominación o arrebato místico incontrolable: «El que llega a la isla se arriesga a un loco rapto, casi sin saber cómo, llevado por las aguas de diamante sobre la

\footnotetext{
${ }^{17}$ Delos, según la mitología, emergió enganchada en las púas del tridente de Poseidón, pero fue una isla flotante hasta que Zeus la ató con cadenas al fondo del mar. En el poema de Sánchez Robayna la describe como una isla flotante que imanta hacia su centro a quien la visita: «Y la barca avanzaba, / avanzaba imperiosa, / como imantada a un punto, su fin fiel.» (2010: 131). Mencionamos aquí algunas referencias, que probablemente consideraría Sánchez Robayna en la génesis del poema: la serie «Gimnopedia» de Yorgos Seferis («Nos hallamos de pronto desnudos sobre la piedra pómez / mirando las islas emergidas / mirando hundirse las rojas islas / en su sueño, en nuestro sueño.» (2012: 151)); o el largo poema El archipiélago, de Hölderlin.

${ }^{18}$ En un poema de la misma serie, «Llega a un lugar de encuentro con el comienzo de lo terrible», sitúa el centro inmanente de lo sagrado en el cabo de Sunion, enclave del templo de Poseidón: «Es el secreto hiriente de los cielos. / Es el templo del templo, es el comienzo / de la unidad, la alianza. Es el lugar / del encuentro, la paz terrible de Sunion» (2010: 119).

${ }^{19} \mathrm{La}$ asociación del espacio insular a lo numinoso será retomada en uno de los fragmentos de Cuaderno de las islas: «Si lo que vuelve sagrado a un lugar es, ante todo, su clausura (fermeture), según Gilbert Durand, nada más numinoso que una isla» (2011: 46).

${ }^{20} \mathrm{Al}$ hilo de nuestra argumentación, un instante clave sobre la experiencia de lo sagrado vinculado al paisaje insular en Cuaderno de las islas (2011) es aquel fragmento en que el poeta medita sobre el llamado «sentimiento oceánico» como «sensación religiosa» de lo eterno: «Tiendo a pensar que las islas proporcionan a ese sentimiento -ligado para Michel Hulin a la dilatación o expansión de las fronteras del Yo- más causalidad, más sustrato o ámbito físico que los territorios continuos, aunque sólo sea por el hecho de que el mar envolvente hace más inmediata o directa la sensación aludida.» (2011: 25).
} 


\section{Tropelías. Revista de Teoría de la Literatura y Literatura Comparada, 29 (2018) 73 La experiencia (y contemplación) de lo sagrado en la obra poética de Andrés Sánchez Robayna}

limpidez del mediodía» (2010: 225). En otro sentido, en «Patmos» ${ }^{21}$, durante su inquietante peregrinar en busca de la Nada, el sujeto poético (en palabras de Juan Goytisolo: «peregrino de luz» y «pastor de silencios» (2011)) dialoga con su conciencia acerca de la revelación de un posible dios insular, ese «dios del venir» (1999: 265) juanramoniano sentido entre las manos:

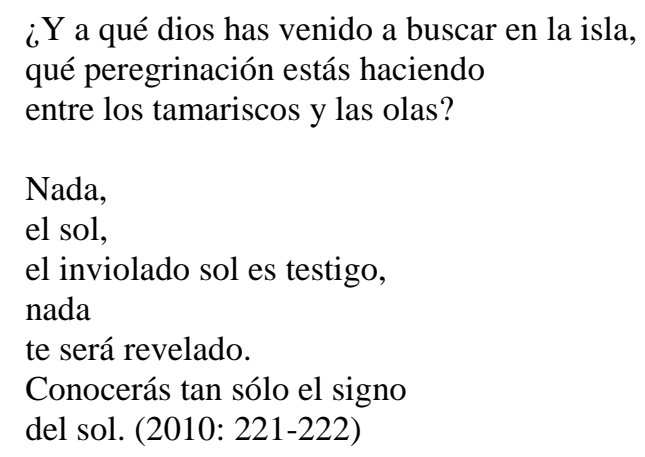

El paisaje insular, además de espacio fenomenológico de revelación de la sacralidad, representa el ámbito de la suspensión temporal a través del silencio: materia natural del poema y germen de la revelación de lo sacro. Así lo desvelaría también en Cuaderno de las islas: «En ningún lugar de la tierra oíste el silencio de manera más honda que en la isla de Lipsí, junto a Patmos. Incluso el sonido de las olas se escuchaba como un eco del silencio» (2011: 67).

En La sombra y la apariencia, lo sagrado se manifiesta asimismo a través de diversos motivos poéticos como la música, en «Homenaje» a Gorecki («La voz asciende, nítida, de cuerpos arrasados, / del humo y la ceniza, de pozos que aún se ahondan, / de muertos que ya nunca volverán a morir, / oh música porosa.» (2011: 53)); o el cielo estrellado, en «De una danza», que esboza los conceptos del eterno retorno y el círculo sagrado («círculo de danza») de Eliade: «una danza te llevó a la raíz de lo infinitamente circular» (2011: 127). En el poema «El vilano» («Sólo tu sombra / pesa menos que tú / sobre la tierra. / Aún menos que tu sombra, / nuestro paso en el polvo» (2011: 149)), el motivo de la sombra avanza la serie «Reflejos en el día de año nuevo», ensayo de poema extenso donde la pulsión de la nada (¿la sombra invisible?, ¿la luz indefinida?, ¿el reflejo de lo visible?, ¿la transparencia?) es origen y centro inmóvil que inocula el Todo. Se trata de una de las composiciones más bellamente escritas por el autor sobre la levedad, el vacío, la desnudez y la apariencia en el sentido místico de lo que había antes del yo: la «nada deseante» como trasposición del Todo. En la composición, paradójicamente, es la misma Nada un todo resacralizado e invisible del que esperamos respuestas. Se aprecian aquí ecos de la «doctrina de la nada» del quietista Miguel de Molinos:

El camino para llegar a aquel alto estado del ánimo reformado, por donde inmediatamente se llega al sumo bien, a nuestro primer origen y suma paz, es la nada [...] Sólo en la nada como espacio

\footnotetext{
${ }^{21}$ En estos versos de «Patmos» resuenan ecos de varias tradiciones: en el primer verso, «Al principio fue un nombre, su sordo resonar» (2010: 219), late el pensamiento de san Juan de la Cruz; en «como si se tratara de la luz final» (2010: 219), El Apocalipsis de san Juan; o, finalmente, el tono elegíaco de «Patmos», de Hölderlin: «Nah ist / Und schwer zu fassen der Gott» («El dios está cercano / y es difícil de alcanzar» (2002: 212)).
} 
realmente abierto a la suspensión del espíritu reina el perfecto y verdadero dominio de uno mismo y el desapego de la identidad. (2010: 169-170)

Como en el caso del místico aragonés, en «Reflejos en el día de año nuevo» hallamos la celebración de la negación (y su nombrar), que al ser entrevista -pese a su transparencia- cobra paradójica presencia a través de la escritura:

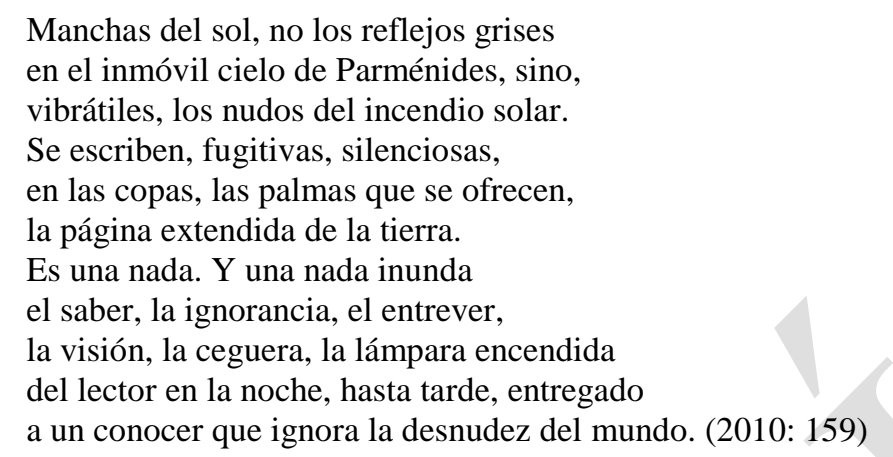

Finalmente, en los versos de Nuevos poemas (2011-2015), se vislumbra una nueva vía poética del autor con una mayor presencia de lo sagrado, intuida a veces desde su búsqueda constante y el sentimiento doloroso de su pérdida. Así, en «Fragmento 1», la revelación de lo sagrado y su trascendencia salvífica se descubren de nuevo a través del oído con la presencia de la campana y el acompasamiento de su tañido: «Y de pronto campanas, la llamada, / era acaso el aviso de otra luz, / en el terso tañido resonaban / la alegría que bulle» (2015: 269). De modo similar, en «Fragmento 2», la llamada de la campana nos suspende en un tiempo interior otro: «El tañido es una brizna de la duración / en la reverberante luz del tiempo» (2015: 271).

En definitiva, Sánchez Robayna representa al poeta moderno que, situado entre la esfera de lo real-visible y lo imaginario-invisible de lectura analógica, entiende los límites de la razón interpretativa, aumenta la sensibilidad para con lo real, interioriza la experiencia, adivina -tras un proceso de ascesis personal- la contingencia de regreso al origen y -buscador (como un falso sacerdote) de lo interior en lo exterior- alcanza, a través de la auscultación en espacios privilegiados, un posible «estado de escritura», de reflexión y de conocimiento diferenciado. Hay que remarcar, además, que esta tentativa del poeta canario debe ser sustancialmente apreciada, sobre todo frente al marasmo poético que ha supuesto la omnipresencia (en los medios y en nuestra crítica) de la llamada «poesía de la experiencia», representada por Luis García Montero, quien recientemente ha llegado a formular estas declaraciones, tan poco respetuosas hacia otra línea de poesía más reflexiva, de mayor rigor estético y más alto vuelo que la que él y los mercaderes de la costumbre ponderan: «Lo de sacralizar la poesía es una trampa en la que no comprendo cómo llegan a caer los poetas» (García Montero, 2017). Ante tal subversión de la idea de lo sagrado o ante su amenazante desaparición, uno se adhiere y acoge aún con mayor estima a la idea de que el verdadero y único designio del poeta moderno ha de ser derribar la barrera de la realidad fenomenológica para acceder a una transrealidad, 


\section{Tropelías. Revista de Teoría de la Literatura y Literatura Comparada, 29 (2018) 75 La experiencia (y contemplación) de lo sagrado en la obra poética de Andrés Sánchez Robayna}

más allá de la cárcel de los sentidos (o la realidad experimentable) y de lo puramente racional $^{22}$. Y, puesto que la experiencia de lo sagrado y su manifestación fundamentan ontológicamente el mundo, el propósito de la literatura debe pasar por la misteriosofía provisional de descubrir lo sagrado en lo real, retirando así el velo que oculta ambas naturalezas; no para revelarlas, sino -como dijo el poeta canario en Variaciones sobre el vaso de agua- para «habitar su misterio» (2014: 15): ese misterio del objeto y de su heideggeriano estar-en-el-mundo en un continuo interrogarnos. Las palabras del propio poeta lo suscriben:

La nuestra es, se diría, una cultura de la desilusión (de la utopía irrealizada) que necesita reencontrarse a sí misma. Y que no lo hará tal vez si no reencontrando lo sagrado, las fuerzas de una espiritualidad capaz de destruir los límites que separan al hombre de sí mismo y lo han alejado de su conciencia de la temporalidad y de la muerte. (2008: 362)

Como se percibe a través de su testimonio, hay en la poesía y en los ensayos de Sánchez Robayna cierto sentimiento elegíaco por la actual ausencia de sentido religioso ante la naturaleza, y por la falta de capacidad por parte del hombre de nuestro tiempo para «ver» las analogías secretas entre mundos. No obstante, como contrapartida, se adivina en los versos de este apologeta del fervor el mensaje esperanzador de que es posible en nuestros días otra vivencia de lo sagrado a nivel individual. Así lo aprecia el poeta canario, y así lo entendió también Stevens: «Cuando se deja de creer en dios, la poesía es esa esencia que ocupa su lugar para que la vida resulte aceptable» (2002: 37). La experiencia (y la contemplación) íntima de lo sagrado, la celebración de otra forma ${ }^{23}$ de estar en el mundo y, sobre todo, la invitación perpetua a su desciframiento nos lo aseguran. Sin duda, lo sagrado está ahí, llamándonos: en las islas, en la luz, en el rayo luminoso, en la duna, en la roca, en el cielo estrellado o en esas nubes de docta ignorantia que sobrevuelan sus versos.

\section{Bibliografía}

BLANCHOt, M. (2007): La parte del fuego. Madrid, Arena Libros.

BONNEFOY, Y. (2014): El territorio interior. Madrid, Sexto piso.

Eliade, M. (1998): Lo sagrado y lo profano. Barcelona, Paidós, reed., 2014.

FERnÁNDEZ CASANOVA, M. (2005): «...Sentidos que no sé: El pensamiento poético de Andrés Sánchez Robayna», Revista Hispánica Moderna, 58. Columbia University, Hispanic Institute, pp. 135-158.

\footnotetext{
${ }^{22}$ En las últimas líneas de este estudio, querría remarcar como idea clave que -además de como una forma de resacralización del mundo- la dimensión sagrada de lo poético en Sánchez Robayna se muestra también bajo el mismo designio que J. Talens plantea sobre la cuestión en El sujeto vacío, es decir como una vía de acceso a un conocimiento otro: «La insistencia en el papel de lo sagrado (“toda poesía es religiosa”, decía Sánchez Robayna en la entrevista citada) tiene esa función; no se trata de reivindicar para la poesía un lugar de creencia, sino un dispositivo de conocimiento diferenciado» (2000: 316).

${ }^{23}$ En un sostenido diálogo entre el pintor Antoni Tàpies y Valente en otoño de 1995, el poeta identificaba lo sagrado con una actitud ante la dimensión de lo poético y otra forma de estar-en-el-mundo: «lo que es sacro es la actitud, porque no estás operando con un procedimiento racional. Estás afrontando una realidad que desconoces con instrumentos que no se fundan en la razón» (Valente, 1996: 14).
} 
GARCíA Montero, L. (2017): «Cuando la poesía suena a falso, es necesario cambiar o callar», entrevista de F. ARAMBURU, El Cultural, en http://www.elcultural.com/revista/letras/LuisGarcia-Montero-Cuando-la-poesia-suena-a-falso-es-necesario-cambiar-o-callar/39753 (última consulta 01-07-2017).

Goytisolo, J. (2011): «Pasajero de la luz. La sombra y la apariencia», El País (11/01/2011). https://elpais.com/diario/2011/01/08/babelia/1294449144_850215.html (última consulta 18-112017).

Herbert, G. (2014): Antología poética, ed. M. Ruiz Albarracín y S. SAnz. Barcelona, Animal sospechoso.

HÖlderlin, F. (2002): Antología poética, ed. F. BERMúdez CAÑETE. Madrid, Cátedra.

JABÈS, E. (2002): Un extranjero con, bajo el brazo, un libro de pequeño formato, trads. C. GonZÁlez De URIARTE - M. PRIVAT, Barcelona, Galaxia Gutenberg.

JiMÉNEZ, J. R. (1999): Lírica de una Atlántida. Barcelona, Galaxia Gutenberg.

KANDINSKY, V. (1982): De lo espiritual en el arte. Madrid, Alianza.

LA CRUZ, J. DE (1991): Obras completas. Salamanca, Sígueme Ediciones.

LAGUiAN, C. (2015): «La resacralisation du cosmos dans la poésie d'Andrés Sánchez Robayna», en B. HidAlgo BACHS, ed., Écritures poétiques et écritures du sacré: interactions. París, Michel Houdiard Éditeur, pp. 273-291.

LE Bigot, C. (2015): «Le sacré comme tension entre l'imaginaire et la visée ontologique: l'exemple d'Andrés Sánchez Robayna», en B. HidALgO BACHS, ed., Écritures poétiques et écritures du sacré: interactions. París, Michel Houdiard Éditeur, pp. 64-75.

Molinos, M. de (2010): Guía espiritual. Valladolid, Maxtor.

Morelli, G. (2009): «ASR, Il libro, oltre la duna», Poesia, 235. Milán, p. 62.

OtTo, R. (2000): Lo santo. trad. F. VELA, Barcelona, Círculo de Lectores.

Palenzuela, N. (1993): Andrés Sánchez Robayna. La sobreiluminación de la materia. La Laguna, El Castillo Estrellado.

SÁnchez Robayna, A. (1996): La inminencia (Diarios, 1980-1995). Madrid, Fondo de Cultura Económica.

- (2004): En el cuerpo del mundo. Barcelona, Círculo de Lectores / Galaxia Gutenberg.

(2008): Deseo, imagen, lugar de la palabra. Barcelona, Círculo de Lectores / Galaxia Gutenberg.

- (2010): La sombra y la apariencia. Barcelona, Tusquets.

- (2011): Cuaderno de las islas. Barcelona, Lumen.

- (2015): Al cúmulo de octubre. Madrid, Visor.

SANTA ANA, M. (2002): «Es preciso no confundir tradición con tradicionalismo (Entrevista a Andrés Sánchez Robayna)», La Página, 50. Santa Cruz de Tenerife, pp. 37-43.

SEFERIS, Y. (2012): Mysthistórima. Poesía completa, trads. S. AnciRA Y F. SEgovia. Barcelona, Galaxia Gutenberg. 
Stevens, W. (2002): Aforismos completos, trad. D. AguiRre. Barcelona, Lumen, $2^{\mathrm{a}}$ ed., 2011.

- (2006): De la simple existencia. Antología poética, ed. A. SÁNCHEZ RoBAYNA. Barcelona, Debolsillo.

TALENS, J. (2000): «El sonido de la visualidad. El iconotexto sonoro de Andrés Sánchez Robayna», en El sujeto vacío. Madrid, Cátedra, pp. 312-320.

TÀPIES, A. - VAlente, J. A. (1996): Comunicación sobre el muro. Barcelona, Ediciones de la Rosa Cúbica, $2^{\text {a }}$ ed., 2004.

VAlente, J. A. (2000a): Variaciones sobre el pájaro y la red (precedido de La piedra y el centro). Barcelona, Tusquets.

- (2000b): Fragmentos de un libro futuro. Barcelona, Galaxia Gutenberg.

VILLER, M. (1990): Dictionnaire de la spiritualité. París, Éditions Beauchesne.

XIRAU, R. (2001): «De lo sagrado», en Entre la poesía y el conocimiento. México, D. F., Fondo de Cultura Económica, pp. 297-308. 